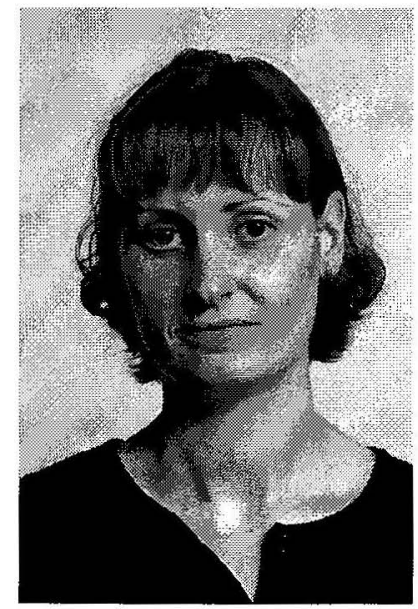

\title{
COACHING MODEL OF PERFORMANCE APPRAISAL: A LOCAL CASE STUDY
}

\author{
Lichelle Meyer \\ Paul Hursthouse \\ Faculty of Business and Computing \\ Eastern Institute of Technology
}

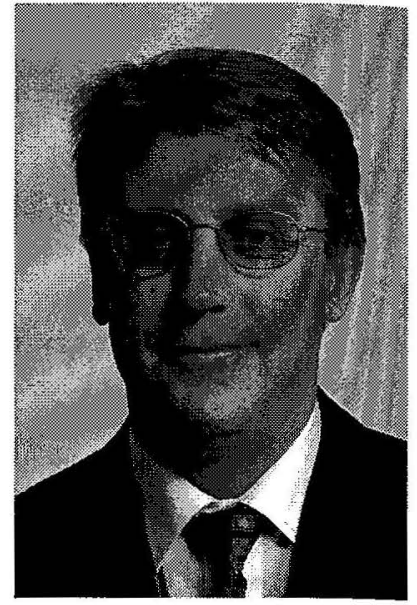

\begin{abstract}
The performance appraisal process is viewed by many as a key management tool that can enhance the development, communication, and implementation of an organisation's strategy, yet critics still debate the benefits. This paper uses a case study to explore the perceptions of staff of changing from a "Traditional" to a "Developmental" approach of performance appraisal.

The case organisation updated their performance appraisal system by utilising technology, refocusing the performance appraisal competency areas and increasing the frequency of the appraisal process. The changes reflect the emerging trends of the performance appraisal process.

Exploratory research was undertaken to determine whether these changes were viewed by staff and management as a positive improvement and whether the change supported contemporary performance appraisal initiatives commented upon within the literature.
\end{abstract}

\section{Introduction}

Increasingly, organisations are integrating the performance appraisal process into standard operating procedures. However, the performance appraisal process is often perceived as a stressful and confrontational activity (Koziel, 2000), nevertheless when implemented effectively, this process can be a valuable tool for management. In an effort to improve their performance appraisal process the Hawke's Bay Regional Council has recently adopted some new initiatives. The Hawke's Bay Regional Council is a local Government body that deals with Hawke's Bay's environmental issues, including water, air, and coastal resources, and employ approximately 100 employees. "Our vision is for a region that develops and prospers within a clean and healthy environment" (Hawke's Bay Regional Council, 2002).

\section{Literature Review}

\section{Purposes for Conducting Performance Appraisals}

The intention of the performance appraisal process in many countries is based on a similar fundamental premise: how to control individual employees in order to achieve maximum performance (Milliman, Nason, Zhu, \& De Cieri, 2002).

"Grote (1996) explains that before World War II, performance appraisal systems could only be found in a small number of companies" (Davis, 2001). Performance appraisals have developed into a multitude of activities through which organisations endeavour to assess employees and develop their competence, enhance performance, and distribute rewards. This includes administrative activities, promotional considerations, disciplinary grounding, training needs analyses, transfers, and terminations (Weiss, 2001).

Many authors outline similar rationalisations as to why organisations will implement the performance appraisal concept. Primary purposes for conducting performance appraisals include increasing the effectiveness of recruitment and selection, identifying training and development needs, the upgrading of skills and knowledge for greater employee involvement in decision making and contribution, progress towards goals and objectives, administration and documentation for legal purposes, receiving subordinate expression (feedback), to simply communicate and 'touch base' with employees, the resolution of working relationship difficulties, and planning accurate human resource budgets (Foster, 2002; Joinson, 2001; Mani, 2002; Messmer, 2000; Milliman, et al., 2002). 


\section{Approaches}

to

Conducting

Performance Appraisals

There have been two paramount approaches to performance appraisal. The first is known as the traditional approach. This concept is essentially concerned with the overall organisation and past employee performance. The second is the developmental approach. This focused on the employees as individuals and has been forward looking through the use of goal setting and development (Hansen, 2002).

The traditional approach to performance appraisal focused on evaluating performance for the purposes of promotions, transfers, rewards, feedback, diagnosing training needs and the like, and was generally bound to remuneration. The disadvantage of this was that "dealing with salary generally overwhelmed and blocked creative, meaningful, or comprehensive consideration of performance goals" (Hansen, 2002). Emphasis on past performance, with little focus on future performance and objectives, limited the advantages of the performance review. The intention of the traditional performance appraisal was essentially to maintain minimum standards for the job and ensure control was exerted over the employee. Overall, the traditional performance appraisal endeavoured to appraise past and current performance, however, these appraisals were often viewed as an opportunity to criticise rather than give recognition or meaningful support for performance improvement (Performance Appraisal Services, 2002).

In contrast, the developmental approach encompasses aspects of the traditional approach, with additions. It includes a greater emphasis on employee development, motivation and satisfaction. The developmental approach allows the opportunity for employees to express their concerns and discuss their career goals. It also attempts to open the communication channels between employees and their managers.

During the progression from power and status to growth and development, technology has had a major impact on the approach and process of performance appraisals. Over the past few decades, technological developments have had a major impact on the workplace; "in the past and particularly now, technology has influenced how people work, what they do, and how their performance is monitored and evaluated" (Hesketh \& Neal, 1999, p. 21).

Electronic monitoring of performance efficiently records large amounts of data on employee performance, and mediates the feedback process, by recording and aggregating performance ratings and written observations, and making the information available online and faster (Fletcher, 2001). The Internet and Intranet systems have the advantage of quick and open communication.

"It seems possible that there is less evaluation apprehension and less emotion in getting feedback from a computer and also that a computer-based system helps focus raters' attention on job-relevant behaviours, reducing the influence of potentially biasing interpersonal cues" (Fletcher, 2001). However, Weisband and Atwater (1999, cited in Fletcher, 2001) found that self-rating tended to be more 'inflated' and less accurate in electronic communication in comparison to a face-to-face approach.

"The writer's block that often accompanies performance reviews is virtually eliminated by the [appraisal software] Intelli-Text Designer" (Dutton, 2001). This type of computer software can provide managers with prompts to 'pinpoint' other performance areas for discussion. These observations can also be summarised into evaluation text - "managers have the options of generating their own supporting text or customizing the existing text to ensure that 'cookie-cutter' evaluations are avoided" (Dutton, 2001).

Ideally, performance-appraisal software streamlines the evaluation process, reduces paperwork, and encourages objectivity; but the gains aren't givens. Managers have to spend some time tailoring the systems to their own workforces. If they don't, says Gene Drumm, senior partner with the Vector Group, Inc. in Denver, "it's a more efficient way of doing a bad process" (Dutton, 2001).

\section{Frequency of Performance Appraisal}

Research conducted has disclosed that in practice, a lot of performance appraisals are conducted only on an annual and perhaps perfunctory basis (Pettijohn, et al., 2001). "However, confusion continues concerning just what encompasses performance appraisal. Is it a one-time meeting annually or a systematic process of ongoing feedback?" (Davis, 2001). Effective performance appraisals should go beyond the annual 'form-filling' interview, it should be an ongoing process of individual and professional development (Davis, 2001).

Given the positive results attribufted to performance appraisals, one could reasonably expect that organizations would devote considerable resources to the appraisal process. Correspondingly, it may be anticipated that appraisals are generally conducted on a frequent basis, are well-planned and conceived, and that the appraisal results are used in such human-resourcemanagement contexts as improving future performance or determining rewards. Yet Morris, Davis, Allen, Avila, and Shapman (1991) discovered that when performance appraisals are conducted, $73 \%$ of the time they occur two or fewer times per year (Pettijohn, et al., 2001, p. 338). 


\section{Advantages of Performance Appraisal}

Performance appraisals have been credited with improving performance and building both job satisfaction and organisational commitment (Pettijohn, et al., 2001). Good appraisals will give the opportunity to review past performance, give feedback and coach, plan activities/commitments and set goals, and foster healthy relationships.

Emerging data from research reveals that feedback is a key driver for continuous learning, creativity and, ultimately, customer satisfaction (McIntosh, 2001). Feedback information assists employees evaluate their own behaviour, improve, and increase performance (Pettijohn, et al., 2001).

"Nemeroff and Wexley (1979) found that differences existed in appraisal perceptions between managers and staff and that employees felt more satisfied with appraisals when there were opportunities to participate in the process" (Wright, 2002, p. 184). Employees commonly require an opportunity to discuss areas that need improvement, ways to improve performance, and suggest how managers can improve training techniques. Appraisers commonly want to contribute to an effective employee and a successful organisation. Two-way communication would help improve not only the employee's performance but also the organisation's (Koziel, 2000).

"How then does something with such potential for success create so much dissatisfaction, lowered morale and genuine disruption in the workplace? ... The transition from theory to application is disjointed, and the practices used to facilitate and support feedback are flawed" (McIntosh, 2001).

\section{Disadvantages of Performance Appraisal}

Marshall and Wood (2000) ascertain the lack of success organisations have with the performance appraisal review is an unrelenting element of disappointment to both practitioners and researchers. "Research has produced many improvements in the mechanics of appraisal, but many feel that the process of appraisal is still far less effective than it should be" (Marshall \& Wood, 2000, p. 62).

Muczyk and Gable (1987, cited in Pettijohn, et al., 2001), state that an organisation's success or failure can often be determined by the ways in which employee performance is managed. "In general, performance appraisals have been described as the human resource program everyone hates" (Pettijohn, et al., 2001, p. 356). The most common complaints and frequently cited drawbacks of the performance appraisal process include:
- Subjectivity - personal values and bias can replace organisational standards.

- Are all the same.

- Lack of communication means employees may not know how they are rated.

- Make distinctions without a real difference.

- Standards and ratings tend to vary widely and, often, unfairly.

- Are not timely enough.

- Belittle people.

- Ignore the system.

- Are used for too many purposes that often conflict (Kennedy \& Dresser, 2001; Oberg, 2002).

"A major and valid criticism of appraisals is that they tend to discourage collaboration" (Segal, 2000). Performance appraisals essentially focus on individual achievements, hence, result in a self-focus rather than a team focus (Segal, 2000).

Critics also contend that appraisals are too subjective ... Employers can minimize the inherent but necessary risk of considering subjective factors by measuring achievement in terms of specific behaviors. In other words, employers can increase the objectivity of the appraisal process by focusing on specific employee behaviors, as opposed to general personality traits that flow from those behaviors (Segal, 2000).

Another fundamental problem with the appraisal process is that many organisations are utilising the performance reviews as a 'delivery vehicle' for too many activities, therefore coverage on employee performance and improvement becomes restricted (McIntosh, 2001).

The conventional performance appraisal system is more like gambling than an objective observation process. It is distorted by evaluator bias and more often reflects the unpredictability of the organization's dynamics. Many employees are skeptical of the evaluation results and even more doubtful of the ability of managers who indulge in the annual flurry of paper (Gray, 2002).

There are common sources of error in conducting performance appraisals, as manager's can often distort their evaluations during the process. These errors include:

- Management Attitude.

- Halo Effect. 
- Central Tendency.

- Recency Effect.

- Leniency and Strictness.

- Similarity and Dissimilarity.

- Prejudice and Bias (Stone, 1998).

\section{Research}

\section{Coaching Model Performance Appraisal Process}

Until October 2001, the Hawke's Bay Regional Council conducted performance appraisals once a year. The human resource department considered the 12-month delay between evaluations to be lengthy and too open for appraisal inaccuracy (especially the 'recency effect', whereby a manager can overemphasise the employee's most recent behaviour). Various frequencies were considered and the decision to conduct the performance review three times per year was adopted.

'Coaching Model' is a term used by the Hawke's Bay Regional Council for an appraisal system that was designed by the Human Resource Department. This appraisal process is performed three times annually, with a goal of eliminating the traditional 'managersubordinate' notion. The concept is to develop a dialogue between managers and their employees, rather than intimidate with the dominant assessment focus. They are seeking to evolve from a 'task orientation' (a results based appraisal) and endeavour to involve employee competencies.

The process utilises a computer program, which separates competency areas into twelve categories:

- Quality of Work.

- Planning and prioritising.

- Showing judgement.

- Solving problems.

- Communication.

- Attitude

- Health and safety.

- Issues to be addressed.

- Key responsibilities.

- Training.
- Ability as a manager.

- Yearly summary.

In each category the employee is ranked by three different expectation options: "Exceeds", "Meets", and "Needs Improvement". On-screen boxes are available for both the employee and manager's comments to be typed. Under each competency area, the manager is given prompts that they are able to utilise for assistance in creating dialogue with the employee during the interview. Two cycles had been completed previous to the research project, the second commenced at the end of March, 2002. Although the Coaching Model was a relatively new concept, the Hawke's Bay Regional Council were keen to seek the views of staff and management as to whether this new approach to performance appraisal was an improvement.

\section{Research Method}

In consultation with the Hawke's Bay Regional Council's Human Resource Manager, surveys were developed and distributed to 94 employees across all departments, including managers. The survey included both quantitative and qualitative questions. $47 \%$ of surveys were returned within the allocated time frame.

\section{Findings and Discussion}

\section{Purposes of the Coaching Model}

The Hawke's Bay Regional Council maintains the appraisal is a crucial ingredient in the effectiveness of their operations. Fundamental objectives of the Council's appraisal system are to ensure employees are informed of company expectations and their ensuing performance, to corroborate the Council's core values, to provide coaching tools and opportunities for improving future performance, and to encourage individual effectiveness and overall Council performance (Hawke's Bay Regional Council, 1999). "A properly conducted performance appraisal that is consistently applied throughout the organization can help employers pinpoint the strongest and weakest - employees" (Segal, 2000). Fundamental objectives of conducting performance appraisals are:

- Differentiation - to objectively distinguish between high and low performers.

- Reward - to compensate those that excel in their performance.

- Development - to improve the performance of low performers (develop strengths and conquer weaknesses).

- Feedback - to communicate the outcome of the appraisal to employees, identifying deficiencies, 
opportunities and expectations (Goldstein, 2001; Milliman et al., 2002; McIntosh, 2001; Stone, 1998).

In essence, organisations may not operate as effectively without some means of distinguishing between good and poor performance (Pettijohn, et al., 2001). "The most important purpose or goal of the appraisal is to improve performance in the future" (Bacal, 2002).

Still, organizations want the results that a reliable performance appraisal system can deliver: clear and specific goals so people know exactly what is expected; solid information on just how well they are doing; senior management's awareness of the contributions they have made; data on where they are doing a great job and where some shaping up is needed; fair and equitable pay for performance; and thumbs-up 'attaboy' when they hit a home run (Grote, 1998).

The performance appraisal process is an effective method of communicating and aligning employee behaviour with organisational interests, strategies and objectives for the achievement of corporate goals (Performance Appraisal Services, 2002). As performance appraisals are more effective when aligned with organisational objectives (Stone, 1998) the Hawke's Bay Regional Council has introduced the new Coaching Model appraisal process to better encourage the integration of the core values of the Council into the work conduct and ethics of staff.

"Precise information turns a critique into an opportunity for improvement. Feedback is the number one motivator of people, so developing an effective review system is the key to maximizing the potential of your people" (Shinkman, 2001).

Consistent with a recent survey conducted in the USA (Cleveland et al., 1989), the primary function performance appraisal systems in New Zealand serve is to provide individual employees with performance feedback, including the identification of strengths and weaknesses and giving recognition for good performance (Taylor \& O’Driscoll, 1993, p. 28).

Additionally, the design of the performance appraisal process generates two fundamental questions to be considered by the human resource department, and include:

- should we focus on personality traits, behaviours, work results or a mix?

- how frequently should we evaluate?

The Hawke's Bay Regional Council evaluated these issues when developing the Coaching Model process, resulting in the inclusion of more employee competencies rather than remaining task focused, and increasing employee performance reviews to three times yearly.

\section{Coaching Model Approach}

In an attempt to progress from the 'traditional' approach to performance appraisals, the Hawke's Bay Regional Council's Coaching Model performance appraisal process endeavours to include a greater emphasis on the characteristics or competencies of employees in order for a more holistic appraisal. The Coaching Model process has an inclination towards the 'developmental' approach, seeking to open the communication channels between staff and managers.

Borman and Motowildo (1993, cited in Fletcher, 2001) distinguished between task performance that involves job-specific behaviours and core responsibilities, and contextual performance, involving non-job-specific behaviours such as cooperation, dedication, and enthusiasm (Fletcher, 2001). "Contextual performance is generally thought of as arising from personality and motivation (Conway, 1999), whereas task performance rests on cognitive ability, skill and experience" (Fletcher, 2001).

The Hawke's Bay Regional Council has attempted to evolve from a task orientation based on results, and integrate more 'contextual' performance qualities (which they refer to as employee competencies, such as quality of work, showing judgement, solving problems, communication, and attitude) in the Coaching Model system. The majority of respondents $(60.5 \%)$ felt that the change from a task orientated performance appraisal to a competency-based appraisal had been beneficial. $34 \%$ felt the change was reasonable, and no respondents felt the change was 'definitely not beneficial'. The majority of respondents $(84.5 \%)$ felt that the competency areas included in the new Coaching Model process cover all the necessary issues in order to provide appropriate feedback.

With the use of computer software employees are able to view their performance evaluations and track progress toward set goals. This allows them to make strategic changes to improve their progression, question comments, and correct mistakes in the documentation, "ultimately, a more accurate appraisal is achieved" with the assistance of technology (Dutton, 2001). The majority of respondents in the Council research (53.3\%) felt that the accuracy of performance appraisals under the Coaching Model process is accurate. $40 \%$ of respondents were neutral and felt there had been no change in the accuracy of appraisals, and $6.7 \%$ felt the appraisals were 'less accurate'.

This is consistent with the benefits of appraisal software identified in the literature including providing tools for administration, efficiently tracking performance records, evaluating trends, enabling both managers and employees to access appraisal information without hassle (Fletcher, 2001), and managing the overall review process throughout an organisation (Davis, 2001). The Hawke's Bay Regional Council has utilised a computer program to govern the Coaching Model system, which has eliminated a lot of the standard paperwork. The majority of respondents $(81.9 \%)$ were in support of the software due 
to the ease of use and clear layout. However, a small percentage $(4.5 \%)$ felt it was difficult to use and $13.6 \%$ saw no change.

"For managers, many of whom are uncomfortable giving feedback, performance-appraisal software helps to pinpoint areas that need improvement and communicate the information to their staffs" (Dutton, 2001).

The Hawke's Bay Regional Council's computer program used in the Coaching Model appraisal process provides prompts in each appraising category for managers to refer to during the interview. This confirms Dutton's (2001) view that software can be beneficial to managers in identifying performance areas for discussion.

\section{Coaching Model Frequency}

Because of the yearly duration (and accompanying problems) between each performance appraisal, many organisations are now conducting evaluations more frequently than once per annum. The Hawke's Bay Regional Council's Coaching Model appraisal is conducted three times per annum. This in turn has resulted in staff receiving 'more' feedback (due to the frequency), increasing communication between employees and managers, hence fostering healthy working relationships. "People respond well to criticisms that are specific, prompt and delivered in a considerate manner" (Ilgen, cited in Shinkman, 2001). Respondents commented that the increased frequency of the Coaching Model now addresses performance issues more promptly, allows for development, and provides a formative review rather than a simple summary.

The Hawke's Bay Regional Council research revealed that the increased frequency of the performance appraisal involves a lot more time and effort, therefore the tendency for staff to resent the performance appraisal process, hence suggestions for a decrease in frequency. This, as literature suggests, is a common type of complaint about appraisals (Kennedy \& Dresser, 2001). However, the time factor also showed that staff perceive increased time equalling increased quality - the theoretical 'backbone' to thorough and accurate performance appraisals.

"In other words, if organizations really want to accomplish the various stated purposes of appraisal (e.g., documentation development, subordinate expression, etc.) then organizations need to devote more time and effort to the performance appraisal process to effectively implement these objectives" (Milliman et al., 2002, p. 98).

\section{Advantages of Performance Appraisal}

"Close supervisor-employee relationships have been linked to improved performance and citizenship" (Amsler, Findley, \& Ingram, 2001). The majority of respondents $(93.3 \%)$ in the Hawke's Bay Regional Council research felt comfortable discussing their performance with their manager, and no respondents felt uncomfortable, thus the presumption that the Hawke's Bay Regional Council has fostered healthy working relationships between employees and managers.

For an effective performance appraisal system, it requires a clear purpose that is communicated to employees, a proficient process, and competent appraisers to conduct the assessments. However, the performance appraisal process can only be effective if top management support is evident in order to show commitment to the appraisal process, hence, everyone from the Chief Executive down should receive an annual performance appraisal (Shinkman, 2001).

\section{Disadvantages of Performance Appraisal}

The majority of respondents $(45.5 \%)$ felt that the appraisal interview process takes more time. $31.8 \%$ felt the interview process took less time, $22.7 \%$ felt there had been no change. "For managers, the process is often considered time consuming, and many feel uncomfortable 'grading' their staff. For those being evaluated, there's fear of receiving negative feedback from their supervisors" (Messmer, 2000). However, if more beneficial material can be acquired and improved on from a thorough appraisal then it can be motivating for an employee and therefore beneficial to an organisation, but can be disparaging if summarised into managerial opinion. "...some individuals claim that performance appraisal systems are so fundamentally flawed as to be manipulative, abusive, autocratic and counterproductive" (Segal, 2000). Commonly, the performance appraisal in many organisations is treated as a bureaucratic exercise, therefore conductéd in an arbitrary and perfunctory manner. This behaviour could be based on perceptions that conducting performance appraisals requires considerable amounts of time and effort, generates few rewards, and adds considerably to the manager's level of conflict and stress (Pettijohn, et al., 2001).

Disadvantages of subjectivity and bias (Kennedy \& Dresser, 2001) have been addressed by the Hawke's Bay Regional Council's Coaching Model. More frequent reviews have the potential to reduce the effect of biases, such as the recency effect, which may have been influencing appraisal results previously. The majority of respondents considered the appraisals under the new model to be accurate.

\section{Conclusion}

Milliman, et al. (2002) maintains the performance appraisal process remains a perplexity in the management realm. It is viewed by many as a key management mechanism that can increase the development, communication, and implementation of an organisation's strategy, yet critics debate the benefits in light of the problems, such as the demotivation of employees. "Clearly, performance evaluations have the potential to positively influence employee performance, but an 
important consideration with appraisals is whether they are practiced effectively and in alignment with their intended purposes" (Milliman, et al., 2002, p. 97).

The majority of respondents ( $48.8 \%$ ) felt that the previous appraisal process was 'fair', and the remaining respondents felt the previous appraisal process was 'good' (27.9\%), and 'poor' (23.3\%). However, significantly, a high proportion of respondents $(88.1 \%)$ felt that overall, the Coaching Model had been an improvement. Remaining responses were more dispersed, with $14.3 \%$ of respondents electing the new appraisal process is 'no different', and $4.8 \%$ electing it is worse.

In summary, the performance appraisal, when utilised and implemented properly and for the right reasons, can be effective in improving future employee performance. Yet difficulties arise when objectives of the process are unclear, the process is utilised for too many purposes that conflict, and appraisers are not trained properly for the task at hand. Therefore, the manner in which the appraisal is executed, the training and competence of the appraiser, and the intended objectives of implementing an appraisal process will determine the successfulness of the management of employee performance.

The recent introduction of the Coaching Model means it is too early to attempt to measure whether it has directly improved employee performance. However the research confirms that the accuracy and timeliness of feedback to staff have improved, therefore it is reasonable to expect that improved performance will follow. "We know with certainty that the most powerful leadership tool for improving productivity and increasing employee satisfaction is regular, frequent, and balanced performance feedback" (McIntosh, 2001).

\section{Future Research}

The findings of this research provide insight into the future developments New Zealand organisations may follow in order to improve their performance appraisal system. However, further research could be continued to review the possible solutions organisation's may adopt in order to rectify past performance appraisal 'damage', and to improve future success of the appraisal process. Future research may extend an investigation regarding the impact of the performance appraisal methodology and the manner in which it is practised, the intended purposes of conducting such a process and the actual outcomes, and the required training and coaching needed for appraisers to appraise and evaluate employees effectively.

\section{References}

Amsler, G. M., Findley, H. M., \& Ingram, E. (2001). Performance monitoring: guidance for the modern workplace. Supervision, 62, 3 - 9. Retrieved February 12, 2002 from the World Wide Web: http://www.proquest.com
Bacal, R. (2002). Management file: what is the point of performance appraisal. Retrieved August 27, 2002 from the World Wide Web: http://www.work911.com/perf/particles/perfpoint. $\underline{\mathrm{htm}}$

Davis, J. S. (2001). Approaches to performance appraisal in student affairs. College Student Affairs Journal, 21, 1, 92+. Retrieved September 9, 2002 from the World Wide Web: http://www.proquest.com

Dutton, G. (2001). Making reviews more efficient and fair: performance appraisal software. Workforce. Retrieved August 2, 2002 from the World Wide Web: http://findarticles.com

Fletcher, C. (2001). Performance appraisal and management: the developing research agenda. Journal of Occupational and Organizational Psychology, 74, 473 - 487. Retrieved September 13, 2002 from the World - Wide Web: http://www.proquest.com

Foster, P. (2002). Performance documentation. Business Communication Quarterly, 65, 2, 108 - 114. Retrieved September 9, 2002 from the World Wide Web: http://www.proquest.com

Goldstein, H. (2001). Appraising the performance of performance appraisals. IEEE Spectrum, 38, 11, 61-63.

Gray, G. (2002). Performance appraisals don't work. Industrial Management, 44, 2, 15-17. Retrieved September 5, 2002 from the World Wide Web: http://www.proquest.com

Grote, D. (1998). Painless performance appraisal focus on results, behaviors. HR Magazine, 43, 11, 5255+. Retrieved September 5, 2002 from the World Wide Web: http://www.proquest.com

Hansen, D. (2002). Performance appraisal tips help page. Retrieved March 17, 2002 from the World Wide Web: http://iso9k1.home.att.net/performanceappraisal/sa mple_performance_appraisal.pdf

Hawke's Bay Regional Council's performance management manual (1999). Hawke's Bay Regional Council.

Hawke's Bay Regional Council. Retrieved March 27, 2002 from the World Wide Web: http://www.hbrc.govt.nz

Hesketh, B., \& Neal, A. (1999). The changing nature of performance: implications for staffing, motivation and development. California: Jossey-Bass, Inc.

Joinson, C. (2001). Making sure employees measure up: performance appraisals. HR Magazine. Retrieved August 2, 2002 from the World Wide Web: http://www.findarticles.com 
Kennedy, P. W., \& Dresser, S. G. (2001, December). Appraising and paying for performance: another look at an age-old problem. Employee Benefits Journal, 26, 8 - 14. Retrieved February 12, 2002 from the World Wide Web: http://www.proquest.com

Koziel, M. J. (2000). Giving and receiving performance evaluations. The CPA Journal, 70, 12, 22-28. Retrieved September 9, 2002 from the World Wide Web: http://www.proquest.com

Mani, B. G. (2002). Performance appraisal systems, productivity, and motivation: a case study. Public Personnel Management, 31, 2, 141-159. Retrieved September 5, 2002 from the World Wide Web: http://www.proquest.com

Marshall, V., \& Wood, R. E. (2000). The dynamics of effective performance appraisal: An integrated model. Asia Pacific Journal of Human Resources, 38, 3, 62-87.

McIntosh, S. (2001). Managing without performance appraisals. HR Magazine, 46, 1, 153-154. Retrieved September 9, 2002 from the World Wide Web: http://www.proquest.com

Messmer, M. (2000). Performance reviews. Strategic Finance, 82, 6, 10-12. Retrieved September 9, 2002 from the World Wide Web: http://www.proquest.com

Milliman, J., Nason, S., Zhu, C., \& De Cieri, H. (2002). An exploratory assessment of the purposes of performance appraisals in North and Central America and the Pacific Rim. Human Resource Management, 41, 1, 87-102.

Oberg, W. (2002). Make performance appraisal relevant. Retrieved August 27, 2002 from the
World

Wide

Web:

http://www.unep.org/restrict/pas/paspa.htm

Pettijohn, C., Pettijohn, L. S., Taylor, A. J., \& Keillor, B. B. (2001). Are performance appraisals a bureaucratic exercise or can they be used to enhance sales-force satisfaction and commitment? Psychology \& Marketing, 18, 4, 337 - 364.

Performance Appraisal Services. (2002). Performance appraisal systems. Retrieved March 17, 2002 from the World Wide Web: http://www.performanceappraisal.co.uk /

Segal, J. A. (2000). 86 your appraisal process? HR Magazine. Retrieved August 2, 2002 from the World Wide Web: http://findarticles.com

Shinkman, C. J. (2001). Performance appraisal: a positive approach. AFP Exchange, 21, 2, 78-80. Retrieved September 9, 2002 from the World Wide Web: http://www.proquest.com

Stone, R. J. (1998). Human resource management. $\left(3^{\text {rd }}\right.$ ed.). Australia: John Wiley \& Sons.

Taylor, P., \& O'Driscoll, M. (1993). Functions and implementation of performance appraisal systems in New Zealand organizations. Asia Pacific Journal of Human Resources, 31, 20-32.

Weiss, W. H. (2001, October). Appraising employee performance. Supervision, 62, $10-12$. Retrieved February 12, 2002 from the World Wide Web: http://www.proquest.com

Wright, R. P. (2002). Perceptual dimensions of performance management systems in the eyes of different sample categories. International Journal of Management, 19, 2, 184-193. 